Gut, 1975, 16, 214-219

\title{
Influence of azathioprine on hepatic reserve in chronic active liver disease
}

\author{
LAYTON RIKKERS AND SHEILA SHERLOCK ${ }^{1}$
}

From the Royal Free Hospital, Pond Street, London

SUMMARY The kinetics of hepatic indocyanine green (ICG) uptake have been analysed in 14 patients with chronic active liver disease. The removal of incremental, submaximal ICG doses were compatible with Michaelis-Menten kinetics in approximately $80 \%$ of studies in patients allowing the calculation of the maximal rate of removal (Rmax) and the Michaelis constant $(\mathrm{Km})$. Neither of these variables correlated with other laboratory indices of liver function. Although determinations of Rmax before and after a two-weeks trial of azathioprine therapy were not significantly different, in two patients $R \max$ was markedly reduced by treatment. It is concluded that azathioprine over the short term does not improve the liver's reserve for ICG removal; in fact, in isolated cases this drug may be detrimental.

Indocyanine green (ICG), an organic anionic dye removed from the blood exclusively by the liver, has been a useful tool for the study of hepatic physiology and for the evaluation of patients with liver disease. In fact, the rate of disappearance of ICG from plasma following its intravenous administration is one of the more sensitive indicators of hepatic dysfunction (Leevy, Smith, Longueville, Paumgartner, and Howard, 1967).

Following the demonstration that hepatic uptake of ICG is a saturable process (Hunton, Bollman, and Hoffman, 1961), Paumgartner, Probst, Kraines, and Leevy (1970) utilized classical MichaelisMenten enzyme kinetics to determine the maximal rate of ICG removal (Rmax) from disappearance rates of multiple, submaximal doses. The discovery of a close correlation between regenerating liver mass in the rat and Rmax by Rikkers and Moody (1974a) encouraged the application of this technique to the clinical estimation of hepatic reserve.

The purposes of the present investigation are twofold: (1) to determine if hepatic removal of ICG in patients with chronic active liver disease follows saturation kinetics, allowing calculation of Rmax, and (2) to assess the role of azathioprine in the management of these patients by evaluating the influence of this drug on $R \max$.

Received for publication 22 January 1975.

'Please send requests for reprints to Professor S. Sherlock at the Royal Free Hospital.

\section{Patients and Methods}

PATIENTS

Fourteen patients, eight males and six females, with chronic active liver disease were evaluated. Their ages ranged from 13 to 69 years, and the known duration of liver disease from three months to seven years, exceeding nine months in 11 patients.

In all cases diagnosis was established histologically by percutaneous liver biopsy. All biopsies exhibited piecemeal necrosis, usually with rosette formation, and fibrosis, while 11 displayed disordered architecture consistent with either developing or established cirrhosis. Evidence of portal hypertension or ascites from physical examination, barium studies, or splenoportography could be detected in seven patients. Hepatitis B antigen was present in three cases.

All patients were evaluated with ICG at least once. Three patients were not studied a second time because of haemorrhage from oesophageal varices (one) or unavailability for follow up (two). The remaining 11 patients were divided into two groups: (A) six patients who had not received drug therapy for liver disease over the previous five months, and (B) five patients on maintenance prednisolone, $10 \mathrm{mg}$ per day. The groups were dissimilar with respect to duration of liver disease and incidence of cirrhosis. While all five group B patients had evidence of cirrhosis on biopsy and a history of 
liver disease for more than a year, only three of six group A patients had these characteristics.

Following the initial ICG analysis, azathioprine, $75 \mathrm{mg}$ per day, was administered to all patients. Prednisolone therapy was continued in group B patients. Two weeks later a second ICG study was performed. One patient in group A was analysed a third time; two weeks afterwards prednisolone, 15 mg per day, was added to the azathioprine regimen.

Serum albumin, total bilirubin, and aspartate transaminase (AST) were determined initially and following two weeks of azathioprine treatment.

\section{ICG ANALYSIS}

Solutions of ICG were prepared by the addition of sterile water and $0.5 \mathrm{ml} 10 \%$ human serum albumin $^{1}$ for stabilization to $50 \mathrm{mg}$ vials of ICG. ${ }^{2}$ All solutions were used immediately following preparation. After the intravenous administration of the appropriate dose of ICG, $2 \mathrm{ml}$ of blood was withdrawn at five, 10, and 15 minutes from a peripheral vein into a syringe lined with heparin (bisulphite free). The concentration of ICG of the plasma fraction of these samples was determined spectrophotometrically at a wavelength of $800 \mu$, after appropriate dilution with normal saline. The plasma disappearance rate (PDR), that is, the percentage of ICG plasma concentration removed by the liver per minute, was calculated as the slope of natural logarithm of plasma concentration versus time. Each study consisted of determining the

${ }^{1}$ Lister Institute of Preventive Medicine, Elstree, Herts, England.

${ }^{2}$ Hynson, Westcott, and Dunning, Baltimore, Maryland. plasma disappearance rate for ICG doses of 0.5 , 1.0 , and $5.0 \mathrm{mg}$ per $\mathrm{kg}$ body weight. Individual doses were administered on separate days to allow for complete hepatic excretion of the dye.

\section{DETERMINATION OF MAXIMAL REMOVAL RATE} (Rmax)

The theoretical basis for the determination of the maximal hepatic removal rate of ICG (Rmax) and the Michaelis constant $(\mathrm{Km})$ from plasma disappearance rates of individual, submaximal ICG doses has been detailed in previous reports (Rikkers and Moody, 1974a; Moody, Rikkers, and Aldrete, 1974). In summary, the following calculations are necessary:

(1) The initial hepatic removal rate $(R)$ for each of the three ICG doses is derived by multiplying the plasma disappearance rate times dose; (2) regression analysis of $\frac{1}{R}$ versus $\frac{1}{\text { dose }}$ (Lineweaver and Burk, 1934) provides both $\mathrm{Rmax}\left(\frac{1}{y \text { intercept }}\right)$ and $\mathrm{Km}$ $\left(-\frac{1}{x \text { intercept }}\right)$. Their corresponding units are $\mathrm{mg}$ per $\mathrm{kg}$ per min and $\mathrm{mg}$ per $\mathrm{kg}$, respectively.

The linearity of the Lineweaver-Burk plot, in addition to allowing a reliable estimation of $R \max$ and $\mathrm{Km}$, also validates the conformity of the data to Michaelis-Menten kinetics. Using the analogy of a reaction between substrate (ICG) and enzyme

\begin{tabular}{|c|c|c|c|c|c|c|c|}
\hline \multirow[t]{2}{*}{ Group ${ }^{1}$} & \multirow[t]{2}{*}{ Patient } & \multicolumn{3}{|c|}{ Before Azathioprine } & \multicolumn{3}{|c|}{ After Azathioprine } \\
\hline & & $\begin{array}{l}R \max \\
(m g / k g / m i n)\end{array}$ & $\begin{array}{l}K m \\
(m g / k g)\end{array}$ & $\boldsymbol{r}$ & $\begin{array}{l}R \max \\
(m g / k g / \min )\end{array}$ & $\begin{array}{l}K m \\
(m g / k g)\end{array}$ & $\boldsymbol{r}$ \\
\hline $\mathbf{A}$ & $\begin{array}{l}\text { AC } \\
\text { WS } \\
\text { AA } \\
\text { MM } \\
\text { SM } \\
\text { CR } \\
\text { Mean }\end{array}$ & $\begin{array}{l}0.73 \\
0.56 \\
0.15 \\
0.71 \\
0.49 \\
0.55 \\
0.53 \pm 0.08^{2}\end{array}$ & $\begin{array}{r}26 \cdot 49 \\
6 \cdot 48 \\
1 \cdot 78 \\
4 \cdot 08 \\
4 \cdot 83 \\
5 \cdot 42 \\
8 \cdot 18 \pm 3 \cdot 71\end{array}$ & $\begin{array}{l}0.999 \\
0.978 \\
0.980 \\
0.999 \\
0.992 \\
0.999\end{array}$ & $\begin{array}{l}0.19 \\
0.56 \\
0.15 \\
0.13 \\
0.58 \\
0.70 \\
0.39 \pm 0.10\end{array}$ & $\begin{array}{l}4.02 \\
5 \cdot 28 \\
1.47 \\
1.54 \\
6.05 \\
8.01 \\
4.39 \pm 1.05\end{array}$ & $\begin{array}{l}0.998 \\
0.999 \\
0.980 \\
0.998 \\
0.999 \\
0.993\end{array}$ \\
\hline $\mathbf{B}$ & $\begin{array}{l}\text { IC } \\
\text { MF } \\
\text { ES } \\
\text { SW } \\
\text { MN } \\
\text { Mean }\end{array}$ & $\begin{array}{l}0.21 \\
0.34 \\
0 \cdot 31 \\
0.21^{3} \\
0.15 \\
0.24 \pm 0.04\end{array}$ & $\begin{array}{l}2 \cdot 11 \\
2.99 \\
5.64 \\
1 \cdot 40^{3} \\
1 \cdot 87 \\
2 \cdot 80 \pm 0.74\end{array}$ & $\begin{array}{l}0.995 \\
0.999 \\
0.999 \\
0.996 \\
0.999\end{array}$ & $\begin{array}{l}0.20 \\
0.47 \\
0.41 \\
0.40 \\
0.10 \\
0.32 \pm 0.07\end{array}$ & $\begin{array}{l}1 \cdot 52 \\
5 \cdot 23 \\
7 \cdot 86 \\
3.97 \\
1 \cdot 11 \\
3.93 \pm 1.24\end{array}$ & $\begin{array}{l}0.996 \\
0.998 \\
0.998 \\
0.995 \\
0.999\end{array}$ \\
\hline $\mathbf{A}+\mathbf{B}$ & $\begin{array}{l}\text { Mean } \\
\text { MG } \\
\text { MA } \\
\text { DH }\end{array}$ & $\begin{array}{l}0.40 \\
0.82 \\
1.07 \\
0.26\end{array}$ & $\begin{array}{r}5 \cdot 73 \\
18 \cdot 92 \\
7 \cdot 23 \\
2 \cdot 39\end{array}$ & $\begin{array}{l}0.998 \\
0.996 \\
0.996\end{array}$ & $0.35 \pm 0.06$ & $4 \cdot 18 \pm 0.76$ & \\
\hline
\end{tabular}

Table I Rmax and $\mathrm{Km}$ values before and after azathioprine treatment

${ }^{1}$ Group A-previously untreated patients; group B-patients on maintenance prednisolone, 10 mg a day, in addition to azathioprine. ${ }^{2}$ Means \pm SEM are presented for all groups.

${ }^{3}$ Calculated from 1.0 and $5.0 \mathrm{mg}$ per $\mathrm{kg}$ ICG doses only. 
(hepatocyte receptor for ICG), Rmax would represent the quantity of receptors while $\mathrm{Km}$ would reflect their relative affinity for ICG (large values for $\mathrm{Km}$ corresponding to low affinity for ICG).

STATISTICAL ANALYSIS

All means are presented with their standard error. Wilcoxon's signed rank test was utilized to determine significant differences between groups $\mathbf{A}$ and $\mathbf{B}$. All variables measured before and after azathioprine were submitted to paired $t$ analysis.

\section{Results}

The hepatic removal of individual ICG doses was exponential in most cases with the correlation coefficient (r) of the plasma disappearance rate plot exceeding 0.995 in 66 of 82 dose studies $(81 \%)$. The mild deviations from linearity which occurred were commoner with the lower ICG doses $(0.5$ and 1.0 $\mathrm{mg}$ per $\mathrm{kg}$ ), but in no instance was $\mathrm{r}$ less than 0.98.

The general conformity of the data to MichaelisMenten kinetics was confirmed by the near perfect linearity of the Lineweaver-Burk regression ( $r$ $\geq 0.995$ ) in 20 of 26 three-dose analyses (table I). Only one patient (SW) displayed an $r$ less than 0.98 for this relation, and, in that case, $R \max$ and $\mathrm{Km}$ were determined from the 1.0 and $5.0 \mathrm{mg}$ per $\mathrm{kg}$ ICG doses alone.

Initial values for $R \max$ and $\mathrm{Km}$ for all patients $(\mathrm{n}=14)$ were $0.47 \pm 0.08 \mathrm{mg}$ per $\mathrm{kg}$ per min and $6.54 \pm 1.94 \mathrm{mg}$ per $\mathrm{kg}$ respectively. $\mathrm{Rmax}$ was significantly higher $(P<0.05)$ for untreated patients (group A) than for those on maintenance corticosteroids (group B).

The influence of azathioprine therapy on hepatic ICG kinetics is shown in table I. After two weeks of

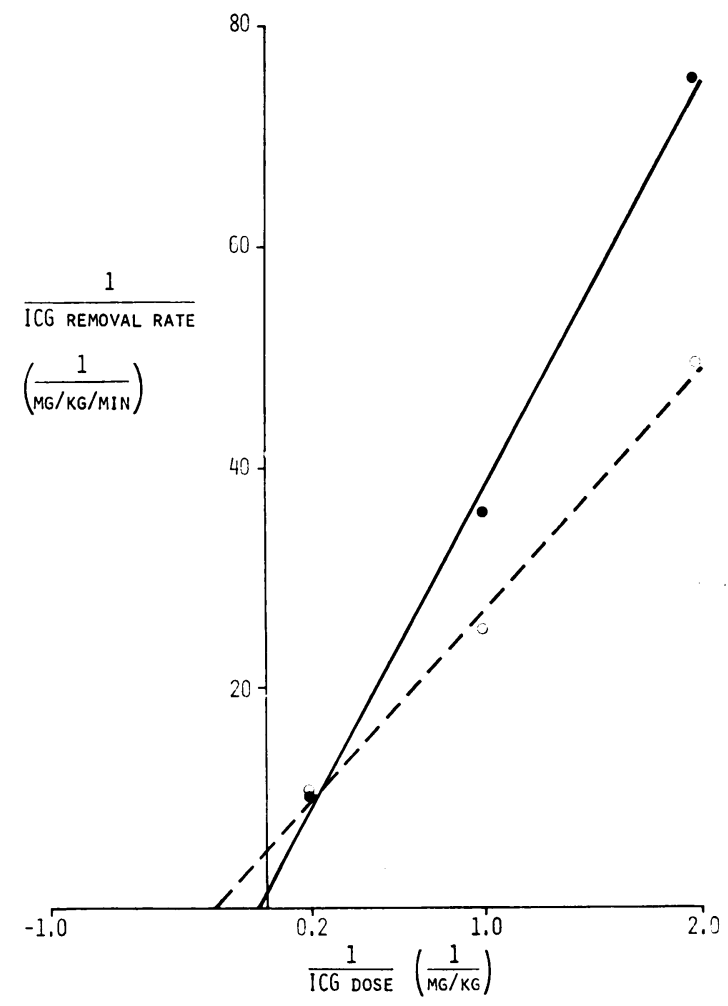

Fig 1 Lineweaver-Burk graphs from ICG analyses in patient AC. Reciprocals of $Y$-intercepts yield values for $R \max$. Solid line represents pretreatment study $($ Rmax $=$ $0.73 \mathrm{mg}$ per $\mathrm{kg}$ per $\mathrm{min})$; interrupted line represents study following two weeks of azathioprine therapy ( $R$ max $=0.19$ mg per kg per min).

\begin{tabular}{|c|c|c|c|c|c|c|c|}
\hline \multirow[t]{2}{*}{ Group } & \multirow[t]{2}{*}{ Patient } & \multicolumn{3}{|c|}{ Before Azathioprine } & \multicolumn{3}{|c|}{ After Azathioprine } \\
\hline & & $\begin{array}{l}\text { Serum Albumin } \\
(\mathrm{g} / 100 \mathrm{ml})\end{array}$ & $\begin{array}{l}\text { Serum Bilirubin } \\
(\mathrm{mg} / 100 \mathrm{ml})\end{array}$ & $\begin{array}{l}\text { Serum } A S T \\
(I U)\end{array}$ & Serum Albumin & Serum Bilirubin & Serum AST \\
\hline $\mathbf{A}$ & $\begin{array}{l}\text { AC } \\
\text { WS } \\
\text { AA } \\
\text { MM } \\
\text { SM } \\
\text { CR }\end{array}$ & $\begin{array}{l}2 \cdot 9 \\
3 \cdot 3 \\
2 \cdot 8 \\
3 \cdot 4 \\
3 \cdot 7 \\
3 \cdot 1\end{array}$ & $\begin{array}{l}2 \cdot 8 \\
2 \cdot 6 \\
3 \cdot 6 \\
4 \cdot 8 \\
1.0 \\
2 \cdot 1\end{array}$ & $\begin{array}{r}188 \\
357 \\
24 \\
104 \\
125 \\
78\end{array}$ & $\begin{array}{l}2.9 \\
3 \cdot 6 \\
3 \cdot 1 \\
4 \cdot 0 \\
3 \cdot 6 \\
3 \cdot 3\end{array}$ & $\begin{array}{r}1.9 \\
2.0 \\
1.3 \\
10.2 \\
1.2 \\
1.3\end{array}$ & $\begin{array}{r}112 \\
190 \\
25 \\
390 \\
32 \\
115\end{array}$ \\
\hline B & $\begin{array}{l}\text { IC } \\
\text { MF } \\
\text { ES } \\
\text { SW } \\
\text { MN }\end{array}$ & $\begin{array}{l}3.6 \\
3.5 \\
3.6 \\
2.5 \\
4.6\end{array}$ & $\begin{array}{l}2.2 \\
0.8 \\
3.8 \\
3.1 \\
8.4\end{array}$ & $\begin{array}{r}27 \\
151 \\
30 \\
211 \\
161\end{array}$ & $\begin{array}{l}3 \cdot 9 \\
3 \cdot 4 \\
3 \cdot 1 \\
2 \cdot 6 \\
4 \cdot 2\end{array}$ & $\begin{array}{l}1.4 \\
1.2 \\
2.8 \\
2.8 \\
6.8\end{array}$ & $\begin{array}{r}26 \\
170 \\
32 \\
127 \\
112\end{array}$ \\
\hline & $\begin{array}{l}\text { MG } \\
\text { MA } \\
\text { DH }\end{array}$ & $\begin{array}{l}3.0 \\
3.9 \\
3.2\end{array}$ & $\begin{array}{l}2.0 \\
0.8 \\
2.9\end{array}$ & $\begin{array}{l}69 \\
42 \\
57\end{array}$ & & & \\
\hline
\end{tabular}

Table II Serum albumin, total bilirubin, and AST before and after azathioprine treatment 


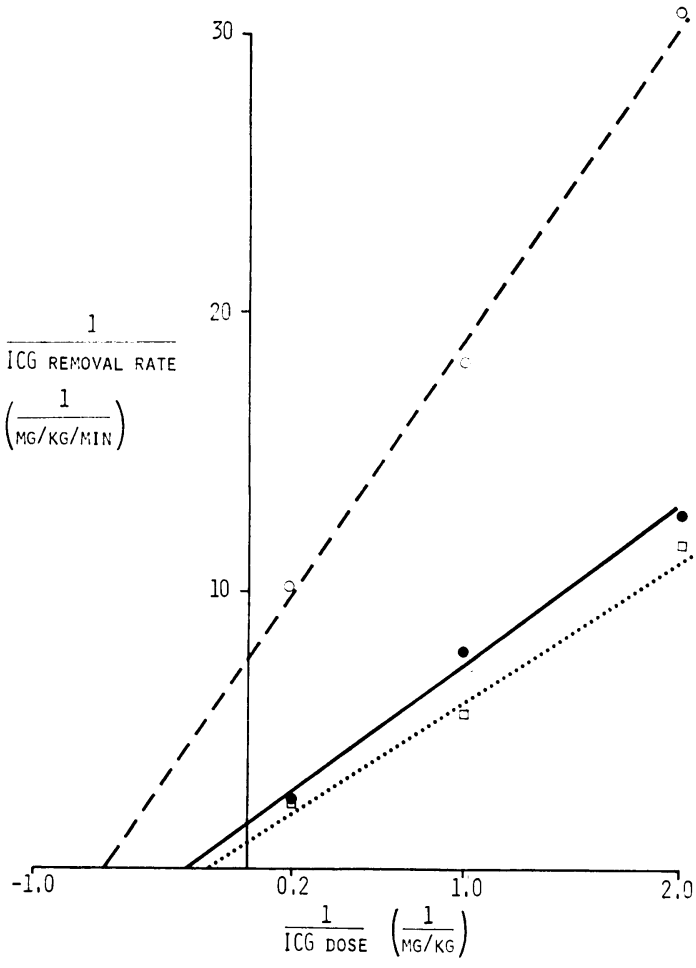

Fig 2 Lineweaver-Burk graphs from ICG analyses in patisnt MM. Reciprocals of $Y$-intercepts yield values for $R \max$. Solid line represents pretreatment study $(R \max =$ $0.71 \mathrm{mg}$ per $\mathrm{kg}$ per min); interrupted line represents study following two weeks of azathioprine therapy ( $R$ max $=0.13 \mathrm{mg}$ per $\mathrm{kg}$ per min); dotted line represents study following two weeks of azathioprine plus prednisolone therapy (Rmax $=0.93 \mathrm{mg}$ per $\mathrm{kg}$ per $\mathrm{min}$ ).

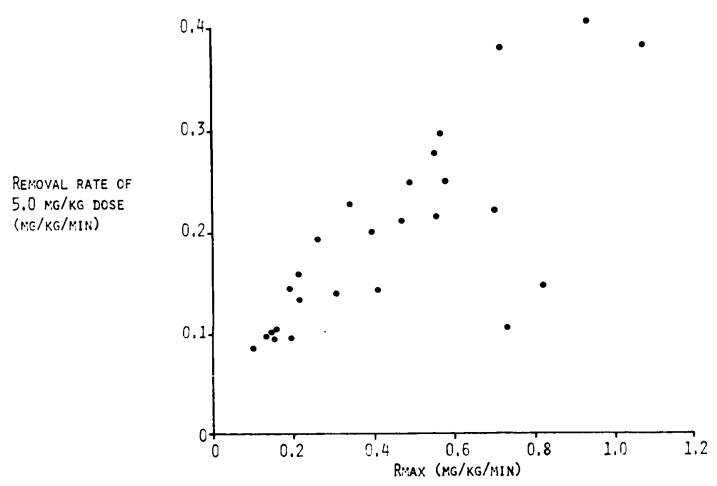

Fig 3 Correlation between $R$ max and removal rate of a $5.0 \mathrm{mg}$ per $\mathrm{kg}$ ICG dosz. Correlation coefficient equals $0 \cdot 76$. azathioprine treatment neither $\mathrm{Rmax}$ nor $\mathrm{Km}$ were significantly altered in group A or group B. Likewise, no effect on these variables could be detected when groups A and B were combined. Similarly, values after treatment for serum albumin, AST, and total bilirubin were not significantly changed from initial measurements (table II).

Two patients (AC and MM) in group A merit individual consideration. Both Rmax and $\mathrm{Km}$ were markedly reduced following azathioprine therapy in both these cases (table I). The Lineweaver-Burk graphs resulting from these studies are presented in figures 1 and 2 . The decreased capacity for hepatic ICG removal was accompanied by elevations in total serum bilirubin and AST in MM, while these parameters were not significantly affected in AC. The alterations in ICG Rmax and $\mathrm{Km}$, serum bilirubin, and AST in MM were reversed two weeks following the addition of prednisolone, $15 \mathrm{mg}$ a day, to the azathioprine regimen. AC was not further evaluated. In the only patient (SW) to display a significant improvement in $R \max$ following azathioprine treatment, the initial measurement was imprecise because of the lack of linearity of the Lineweaver Burk regression.

Comparison of both Rmax and $\mathrm{Km}$ with serum albumin, total bilirubin, and AST revealed no significant relationships. However, a significant correlation ( $P<0.01)$ existed between Rmax and the hepatic removal rate $(R)$ for each of the individual ICG doses. The best correlation $(r=0.76)$ was with the $\mathrm{R}$ of the $5.0 \mathrm{mg}$ per $\mathrm{kg}$ dose (fig 3).

\section{Discussion}

These results indicate that hepatic removal of incremental doses of ICG is consistent with Michaelis-Menten kinetics in most patients with chronic active liver disease, providing a means of estimating a maximal removal rate (Rmax) for this dye. The mean Rmax of $0.47 \pm 0.08 \mathrm{mg}$ per $\mathrm{kg}$ per min calculated for this group of patients is considerably less than the values of $3.6 \mathrm{mg}$ per $\mathrm{kg}$ per min (Paumgartner et al, 1970) and $3.4 \mathrm{mg}$ per $\mathrm{kg}$ per min (Moody et al, 1974) previously established for subjects without hepatic dysfunction. All patients in the present series had Rmax values well below these normal values. Patients in group B, all of whom had histologically proven cirrhosis, exhibited an $R \max (0.24 \pm 0.04 \mathrm{mg}$ per $\mathrm{kg}$ per min) identical to that determined earlier for a population of alcoholic cirrhotics (Moody et al, 1974). The mean Rmax for group A $(0.53 \pm 0.08 \mathrm{mg}$ per $\mathrm{kg}$ per $\mathrm{min}$ ), consisting of both cirrhotic (three) and non-cirrhotic (three) patients, was significantly higher. 
Two theoretical advantages derive from determination of Rmax. First, since Rmax represents the rate of ICG uptake when the hepatic mechanism for its removal is saturated, this measurement should be a reasonable estimate of the hepatic reserve for this function. Second, because saturation is hypothetically attainable despite alterations in liver blood flow or the presence of competitors for hepatic removal, Rmax should be independent of these factors. Kinetic analysis of hepatic ICG removal in experimental animals has supported both of these postulates. A close correlation between Rmax and liver weight has been demonstrated in rats following partial hepatectomy and at various intervals during regeneration, indicating that this parameter, at least in these circumstances, is an accurate reflection of functional hepatic mass or reserve (Rikkers and Moody, 1974a). The organic anions bilirubin and rifamycin, known to compete with ICG for hepatic uptake, do not alter Rmax when simultaneously administered with ICG to normal rats (Paumgartner et al, 1970). In addition, patients with hyperbilirubinaemia secondary to extrahepatic biliary obstruction, but with well preserved hepatocellular function, often have near normal Rmax values (Moody et al, 1974).

Because of the complexity of physiological, biochemical, and metabolic derangements accompanying chronic liver disease, such clear and predictable relationships might not be expected either between $R \max$ and liver mass or between Rmax and other laboratory indices of liver function in patients with these disorders. And, in fact, in the present study no correlation existed between either Rmax or $\mathrm{Km}$ and serum albumin, total bilirubin, or AST. A similar finding for a variety of hepatic diseases has previously been reported (Moody et al, 1974). The fact that the two patients (MM and $M N$ ) with the lowest Rmax values had normal serum albumin levels implies that, even though $R \max$ for ICG may truly reflect the liver's reserve for organic anion uptake, this measurement is not necessarily a reliable indicator of the competence of other hepatic processes. Because of the multiplicity of functions performed by the liver, this same limitation pertains to other quantitative methods such as the galactose elimination capacity (Tygstrup, 1966), and the excretory $\mathrm{Tm}$ for sulphobromopthalein (BSP) (Wheeler, Meltzer, and Bradley, 1960).

Significant disadvantages of this technique are its relatively high cost and the three-day period required for determining Rmax. The cost of the dye alone needed for a three-dose test in a person of $70 \mathrm{~kg}$ is approximately $\$ 75$. Because precise measurement of Rmax requires stable hepatic function and blood flow over the test interval, the method is not applic- able to acute liver disease or other situations accompanied by rapid alterations in these factors. Therefore, an important finding in the present study is the strong correlation between Rmax and the removal rate $(R)$ of a $5.0 \mathrm{mg}$ per $\mathrm{kg}$ ICG dose, making the estimation of hepatic removal capacity for this anion from a single large dose possible in most cases. A similar close relationship between $\mathrm{Rmax}$ and 5.0 mg per $\mathrm{kg} \mathrm{R}$ has been found in a wide spectrum of liver and biliary tract disease by Moody and his coworkers (Moody et al, 1974). In addition, a reliable estimation of regenerating liver mass in the dog from hepatic removal rate of a $10 \mathrm{mg}$ per $\mathrm{kg}$ ICG dose lends further support to the feasibility of a single-dose approximation of hepatic reserve (Rikkers and Moody, 1974b).

Corticosteroids prolong survival and improve standard biochemical tests of liver function in patients with chronic active liver disease (Cook, Mulligan, and Sherlock, 1968; Soloway, Summerskill, Baggenstoss, Geall, Gitnick, Elveback, and Schoenfeld, 1972). These drugs also have a beneficial influence on hepatic organic anion uptake as evidenced by significantly decreased BSP retention, relative hepatic storage (S) for BSP (Cook, Velasco, and Sherlock, 1968), and, in the present study, an impressive increase in ICG $R \max$ in the only patient (MM) studied before and after treatment with prednisolone.

Unfortunately, the relatively high frequency of undesirable side effects associated with corticosteroids limits their usefulness in many patients. Therefore azathioprine, a drug which is free of the complications accompanying steroid therapy, has been utilized in the treatment of chronic active liver disease. However, in a prospective controlled trial, although the combination of azathioprine and low-dose prednisone improved prognosis, patients treated with azathioprine alone fared no better than those given placebos (Soloway et al, 1972).

Because of its questionable efficacy, we have examined the influence of azathioprine on hepatic reserve as measured by ICG Rmax in patients with chronic active liver disease. Following two weeks of treatment with azathioprine we could detect no improvement in Rmax in previously untreated patients (group A), those on maintenance prednisolone (group B), or both groups combined. Thus, it appears that, at least over the short term, azathioprine has no beneficial influence on the liver's reserve for ICG removal in these patients.

The use of azathioprine in various non-hepatic diseases has occasionally resulted in liver toxicity, manifested by portal fibrosis and cholestasis (Du Vivier, Munro, and Verbov, 1974; Zarday, Veith, 
Gliedman, and Soberman, 1972). Although difficult to distinguish from the natural course of the disease, this drug is also thought to have a detrimental effect on hepatic function in some patients with chronic active liver disease (Soloway et al, 1972). Two previously untreated patients (AC and MM) from the present study experienced marked reductions in Rmax following therapy with azathioprine. The depression in Rmax after treatment was accompanied by a worsening of standard liver function indices in one (MM), but not the other (AC). AC was a Negro female aged 13 and MM a 30year-old male Arab. Both had a relatively brief history of liver disease ( $<$ five months) and very active hepatitis biochemically and histologically. AC also exhibited early histological evidence of cirrhosis. Hepatitis B antigen was the aetiological agent in MM while AC displayed immunological aberrations consistent with 'lupoid hepatitis' (elevated titres of smooth muscle, antinuclear, and anti-DNA antibodies, and a total globulin level of $6.0 \mathrm{~g} \%$ ). Before treatment $R \max$ was relatively high ( 0.73 and $0.71 \mathrm{mg}$ per $\mathrm{kg}$ per $\mathrm{min})$ in both cases.

Although the mechanism of azathioprine's proposed hepatoxicity has not been elucidated, it is known that the immunosuppressive activity of this drug, as measured by the rosette inhibition test, is dependent upon adequate hepatic function (Wheland and Sherlock, 1972). If the toxic potential of azathioprine also requires activation by the liver, it is not surprising that an adverse effect of the drug was detected in the two patients with the highest values for ICG Rmax. Another possibility is that the deterioration in $R \max$ in these two patients simply represents progression of their disease. However, the magnitude of the decrease coupled with the short period between analyses makes this unlikely.

Finally, it should be emphasized that patients were evaluated only over a relatively brief treatment interval. What effect long-term azathioprine therapy might have on hepatic ICG extraction is not known.

We would like to thank the Ingram Fund for financial support.

\section{References}

Cook, G. C., Mulligan, R., and Sherlock, S. (1971). Controlled prospective trial of corticosteroid therapy in active chronic hepatitis. Quant. J. Med., 40, 159-185.

Cook, G. C., Velasco, M., and Sherlock, S. (1968). Effect of corticosteroid therapy on bromsulphthalein excretion in active chronic hepatitis. Gut, 9, 270-283.

Du Vivier, A., Munro, D. D., and Verbov, J. (1974). Treatment of psoriasis with azathioprine. Brit. med. J., 1, 49-51.

Hunton, D. B., Bollman, J. L., and Hoffman, H. N. (1961). The plasma removal of indocyanine green and sulphobromopthalein: effect of dosage and blocking agents. J. clin. Invest., 40, 1648-1655.

Leevy, C. M. Smith, F., Longueville, J., Paumgartner, G., and Howard M. M. (1967). Indocyanine green clearance as a test for hepatic function: evaluation by dichromatic ear densitometry. $J$. Amer, med. Ass., 200, 236-240.

Lineweaver, H., and Burk, D. (1934). The determination of enzyme dissociation constants. J. Amer. chem. Soc., 56, 658-666.

Moody, F. G., Rikkers, L. F., and Aldrete, J. S. (1974). Estimation of the functional reserve of human liver. Ann Surg., 180, 592598.

Paumgartner, G., Probst, P., Kraines, R., and Leevy, C. M. (1970). Kinetics of indocyanine green removal from the blood. Ann. N.Y. Acad. Sci., 170, 134-147.

Rikkers, L. F., and Moody, F. G. (1974a). Estimation of functional hepatic mass in resected and regenerating rat liver. Gastroenterology, 67, 691-699.

Rikkers, L. F., and Moody, F. G. (1974b). Estimation of functional reserve of normal and regenerating dog livers. Surgery, 75 , 421-429.

Soloway, R. D., Summerskill, W. H. J., Baggenstoss, A. H., Geall. M. G., Gitnick, G. L., Elveback, L. R., and Schoenfeld, L. J. (1972). Clinical biochemical and histological remission of severe chronic active liver disease: a controlled study of treatments and early prognosis. Gastroenterology, 63, 820-833.

Tygstrup, N. (1966). Determination of the hepatic elimination capacity (Lm) of galactose by single injection. Scand. J. clin. Lab. Invest., 18, Suppl. 92, 118-125.

Wheeler, H. O., Meltzer, J. I., and Bradley, S. E. (1960), Biliary transport and hepatic storage of sulfobromopthalein sodium in the unanesthetized dog, in normal man, and in patients with hepatic disease. J. clin. Invest., 39, 1131-1144.

Whelan, G., and Sherlock, S. (1972). Immunosuppressive activity in patients with active chronic hepatitis and primary biliary cirrhosis treated with azathioprine. Gut, 13, 907-914.

Zarday, Z., Veith, F. J., Gliedman, M. L., and Soberman, R. (1972). Irreversible liver damage after azathioprine. J. Amer. med. Ass., 222, 690-691. 